\title{
Can Endoscopic Appearance, Selective Cytology, and Pathological Sampling During Ureteroscopy Accurately Predict Tumor Grade of Upper-Tract Urothelial Carcinoma?
}

\author{
Kamil Malshy, M.D.*, Omri Nativ, M.D., Ariel Zisman, M.D., Omer Sadeh, \\ M.D., Azik Hoffman, M.D., Gilad E. Amiel, M.D., and Michael Mullerad, M.D. \\ Department of Urology, Rambam Health Care Campus, Haifa, Israel
}

\begin{abstract}
Objective: This study examined the reliability of the various parameters obtained in diagnostic ureteroscopy for upper-tract urothelial carcinoma (UTUC) in predicting the degree of differentiation in the final pathological report after radical nephroureterectomy (RNU).

Methods: We conducted a retrospective review of patients undergoing RNU at a single tertiary hospital between 2000 and 2020. Only patients who underwent preoperative diagnostic ureteroscopy (URS) were included. The results of urine selective cytology, endoscopic appearance of the tumor, and biopsy taken during ureteroscopy were compared to the final pathological report.
\end{abstract}

\footnotetext{
Abbreviations: CIS, carcinoma in situ; CT, computed tomography; HG, high grade; LG, low grade; NAC, neo-adjuvant chemotherapy; RNU, radical nephroureterectomy; TPS, The Paris System; UC, urothelial carcinoma; URS, ureteroscopy; UTUC, upper-tract urothelial carcinoma.
}

Citation: Malshy K, Nativ O, Zisman A, Sadeh O, Hoffman A, Amiel GE, Mullerad M. Can Endoscopic Appearance, Selective Cytology, and Pathological Sampling During Ureteroscopy Accurately Predict Tumor Grade of Upper-Tract Urothelial Carcinoma? Rambam Maimonides Med J 2022;13 (1):eooo2. doi:10.5041/RMMJ.10459

Copyright: (C) 2022 Malshy et al. This is an open-access article. All its content, except where otherwise noted, is distributed under the terms of the Creative Commons Attribution License (http://creativecommons.org/licenses/by/3.o), which permits unrestricted use, distribution, and reproduction in any medium, provided the original work is properly cited.

Acknowledgments: The authors thank Mrs Tatiana Mashiach (Department of Epidemiology, Rambam Health Care Campus) for her statistical assistance.

Conflict of interest: No potential conflict of interest relevant to this article was reported.

* To whom correspondence should be addressed. E-mail: kamilmalshy@gmail.com 
Results: In total, 111 patients underwent RNU. A preliminary URS was performed in 54 . According to endoscopic appearance, $40 \%$ of the "solid"-looking tumors were high grade (HG), while $52 \%$ of those with a papillary appearance were low grade (LG). Positive cytology predicted HG tumors in $86 \%$ of cases. However, $42 \%$ of patients with negative cytology had HG disease. The biopsies acquired during URS showed that HG disease findings matched the final pathology in $75 \%$ of cases. However, $25 \%$ of patients noted as being HG, based on URS biopsies, were noted to have LG disease based on nephroureterectomy biopsies. Full analyses revealed that $40 \%$ of the cases diagnosed as LG based on the URS biopsies actually had HG disease.

Conclusions: Direct tumor observation of papillary lesions, negative cytology, and biopsies indicating LG disease are of low predictive value for classifying the actual degree of tumor differentiation. No single test can accurately rule out HG disease. In light of the rising use of neo-adjuvant chemotherapy in UTUC, a reliable predictive model should be developed that accurately discriminates between HG and LG disease.

KEY WORDS: Diagnostic ureteroscopy, endoscopic appearance, endoscopic biopsy, tumor grade, upper-tract urothelial carcinoma, urine cytology, UTUC

\section{INTRODUCTION}

Upper-tract urothelial carcinoma (UTUC) accounts for $5 \%-10 \%$ of urothelial carcinomas (UC), ${ }^{1}$ with an annual incidence of 2:100,000 in Western countries. ${ }^{2}$ Males have a three-fold increased risk compared to women. 3 The most known risk factors are cigarette smoking, arsenic exposure, Balkan nephropathy, and hereditary non-polyposis colorectal cancer. 4

While in the past radical nephroureterectomy (RNU) with bladder cuff excision was overwhelmingly the treatment of choice, other less invasive treatments were used only for exceptional cases such as a single functioning kidney, bilateral disease, and distal ureteral focal disease; however, in recent years patient-specific strategies have emerged. 5

The updated European Urological Association guidelines of 2021 recommend renal sparing surgeries for low-risk disease (unifocal, $<2 \mathrm{~cm}$, lowgrade [LG] cytology, LG biopsy, and not invasive on computed tomography [CT]), most commonly by ureteroscopic resection or distal ureterectomy, allowing for ipsilateral kidney preservation without oncological compromise. High-risk disease (hydronephrosis, $>2 \mathrm{~cm}$, high-grade [HG] cytology, HG biopsy, multifocal, or previous radical cystectomy for bladder urothelial carcinoma and variant histology) is still treated with RNU as the gold standard, although there is an increasing use of neoadjuvant platin-based chemotherapy. ${ }^{6}$

Given the above, diagnostic ureteroscopy (URS) is almost routinely used in most cases of suspected
UTUC. This procedure provides the surgeon with priceless details: endoscopic appearance, selective urine cytology, retrograde imaging, and, most crucially, tissue biopsy. In addition, accurately identifying patients with high-risk tumors would help select those who may benefit from neo-adjuvant chemotherapy (NAC) prior to surgery and others who may be candidates for renal sparing surgery.

This study was aimed at examining the reliability of the various diagnostic parameters in predicting tumor grade in the final pathological report after radical nephroureterectomy.

\section{PATIENTS AND METHODS}

\section{Study Design and Population}

Following the Institutional Research Board approval (RMB-0254-16), data were gathered from computerized medical files using the specific ICD-9 discharge codes, nephrectomy, nephroureterectomy, and ureterectomy.

The charts of all patients with clinically localized UTUC who had undergone RNU at a single tertiary medical center (Rambam Health Care Campus, Haifa, Israel) between January 2000 and March 2020 were reviewed retrospectively. Surgical procedures were performed by an open or minimally invasive approach per the surgeon's discretion. $\mathrm{Pa}-$ tients with no preoperative diagnostic URS, or patients who had received NAC in an intent to avoid potentially confounding impact on pathologic data, were excluded from the study. 


\section{Diagnostic Ureteroscopy}

Ipsilateral URS involves four steps in the following order: (1) selective urine cytology collection; (2) retrograde uretero-pyelography; (3) full upper-tract inspection for lesions; and (4) lesion biopsy. A semirigid 8/9.8 Fr and $6 \mathrm{Fr}$ flexible ureteroscope (Wolf, Richard Wolf, Berlin, Germany) was used. Tumor biopsies were taken by endoscopic basket, cupbiopsy (BIGopsy Cookmedical@, Bloomington, IN, USA), or forceps.

Biopsies obtained by URS were classified according to the 2004 World Health Organization (WHO) criteria as LG or HG. The biopsy technique and number of biopsies performed were at the treating urologist's discretion.

\section{Primary Endpoint}

The primary endpoint was the ability to accurately predict tumor grade post-RNU in the final pathological report based on selective cytology, endoscopic appearance, and tissue biopsy grade.

\section{Secondary Endpoints}

Secondary endpoints were as follows:

- To determine the association between demographic data and tumor grade,

- To ascertain the status and disease histology for bladder UC, and

- To determine the association between biopsy grade and final tumor stage.

\section{Statistical Analysis}

The association between URS data and final UTUC pathology results was evaluated using the chi-square test. In calculating sensitivity, specificity, and predictive values, the URS biopsy was used as the diagnostic test, and final pathology in RNU tumor grade (high versus low) was used for disease outcomes. $P<0.05$ was considered statistically significant. All statistical analyses were performed using SPSS software (SPSS 25.0; SPSS Inc. Chicago, IL, USA). The predictive quality of each variable was evaluated according to Equation 1:

\section{RESULTS}

The single medical center recorded 111 patients undergoing nephroureterectomy due to UTUC between January 2000 and March 2020. Excluded from the study were 57 patients (insufficient preoperative URS data, $n=53$; receiving NAC, $n=4$ ). The final study population included 54 patients ( 37 men and 17 women) with a mean age of $71.6 \pm 11.21$ (range 4993) years. Selective cytology, endoscopic appearance, and biopsy data were available for 40,37 , and 32 patients, respectively (Figure 1).

Table 1 describes the patients and tumor characteristics. Of note, 10 of the cases were multifocal, and in all of these cases, the renal pelvis was involved. No statistically significant differences were seen between groups regarding age, gender, smoking status, or tumor location (Table 1).

\section{Selective Cytology and Final Pathology}

The final study cohort comprised 40 patients with selective cytology samples. Of these, 7 (17.5\%) with atypical cytology were graded at stage III according to The Paris System (TPS) for reporting urinary cytopathology; final pathology was low grade in 3 and high grade in 4 . Due to the weak significance of the atypical cytology, no further analysis was performed for these 7 patients.

Negative urine cytology was noted in 19 patients (47.5\%; TPS II and V); final pathology was low grade in $11(58 \%)$ and high grade in 8 (42\%). Positive urine cytology was found in 14 patients (35\%; TPS IV and VI) with a final pathology of HG in 12 (86\%) and LG in $2(14 \%)$.

\section{Endoscopic Appearance and Final Pathology}

Endoscopic tumor appearance was documented in 37 patients. Papillary tumor pattern was noted in 27 (73\%), with a final pathology of low grade in 14 (52\%) and high grade in 13 (48\%). Solid-looking tumor growth was seen in 10 patients (27\%), with final pathology of high grade in $4(40 \%)$ and low grade in $6(60 \%)$.

$$
\text { Accuracy }=\frac{\text { True Positive }+ \text { True Negative }}{\text { True Positive }+ \text { True Negative }+ \text { False Positive }+ \text { False Negative }}
$$

(Equation 1) 


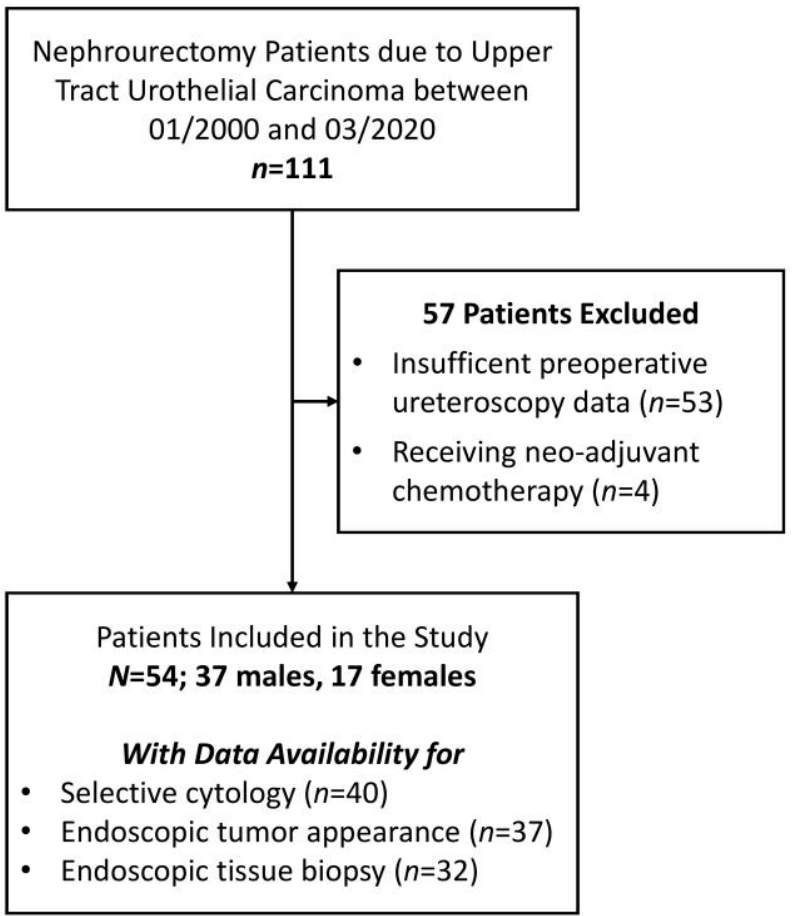

Figure 1. Flow Chart of Patients Who Met the Study Exclusion and Inclusion Criteria.

\section{Tissue Biopsy During URS and Final Pathology}

An endoscopic biopsy was performed in 32 patients, of which 20 (62.5\%) patients were LG. For these 20 patients, final pathology revealed high grade in 8 (40\%) and confirmed low grade in 12 (60\%). Endoscopic biopsy in the other 12 patients (37.5\%) indicated HG tumors, with final pathology revealing 9 $(75 \%)$ being high grade and $3(25 \%)$ as low grade.

Table 2 provides the sensitivity, specificity, positive predictive value, and negative predictive value for the different parameters.

\section{Bladder Urothelial Carcinoma Status and UTUC Grade}

Synchronous or metachronous bladder UC was found in 22 (40.7\%) patients, and constituted 9/23 (39.1\%) of the LG group and $13 / 31$ (41.9\%) of the HG group $(P=1)$. A statistically significant correlation was observed between bladder UC grade and the final UTUC pathology grade: $8 / 9$ (88\%) cases in the LG bladder UC group had low-grade UTUC versus only $4 / 13$ (30.8\%) in the high-grade UTUC $(P=0.011)$.

\section{UTUC Grade and Stage Correlation}

There was a statistically significant correlation in the entire cohort between high-grade UTUC and invasive disease: 22 (71\%) of the patients with highgrade UTUC had T2-T4 stage tumors versus only 9 (29\%) in the low-grade UTUC group $(P=0.0021)$.

\section{DISCUSSION}

Although RNU is still the gold standard treatment for patients with UTUC, the 2021 European Association of Urology guidelines include conservative management as a treatment option in selected patients (solitary lesions $1 \mathrm{~cm}$, LG, non-muscleinvasive lesions at CT scan, and absence of upper urinary tract dilatation). Renal sparing surgery may be a forced compromise for patients with a solitary kidney, severe chronic kidney disease, or significant comorbidities. $^{2}$

Significant advances in endoscopic technology during the last two decades have contributed to increasing diagnostic accuracy and treatment options in the management of UTUC.7 When there is no escape from RNU, peri-adjuvant chemotherapy is a 
Table 1. Demographic Data and Tumor Characteristics on Preoperative Diagnostic Ureteroscopy and Final Pathology.

\begin{tabular}{|c|c|c|c|}
\hline Parameter & $\begin{array}{l}\text { LG in Final Pathology } \\
n(\%)\end{array}$ & $\begin{array}{c}\text { HG in Final Pathology } \\
n(\%)\end{array}$ & $P$ Value \\
\hline Number of cases & 23 & 31 & \\
\hline Age, years & $71.9+11.1$ & $71.5+11.3$ & 1 \\
\hline Male & $13(35.1 \%)$ & 24 (64.9\%) & 0.118 \\
\hline Female & $10(58.8 \%)$ & $7(31.2 \%)$ & \\
\hline Tobacco smoker & 17 (73.9\%) & $13(41.9 \%)$ & 0.08 \\
\hline \multicolumn{4}{|l|}{ Tumor location } \\
\hline Ureter & $12(52.2 \%)$ & 11 (35.4\%) & 0.16 \\
\hline Renal pelvic & $4(17.4 \%)$ & $10(32.2 \%)$ & 0.34 \\
\hline Renal calyces & $3(13 \%)$ & $2(6.4 \%)$ & 0.64 \\
\hline Multifocal & $4(17.4 \%)$ & $6(19.3 \%)$ & 1 \\
\hline Not documented & $0(0 \%)$ & $2(6.4 \%)$ & 1 \\
\hline Bladder UC & $9(39.1 \%)$ & $13(41.9 \%)$ & 1 \\
\hline Low grade & $8(88.8 \%)$ & $4(30.8 \%)$ & 0.0115 \\
\hline High grade & $1(11.2 \%)$ & $9(69.2 \%)$ & \\
\hline \multicolumn{4}{|l|}{ Final stage } \\
\hline $\mathrm{T} 0, \mathrm{Ta}, \mathrm{T} 1$ & 17 (73.9\%) & $9(29 \%)$ [1 CIS] & 0.0021 \\
\hline T2-T4 & $6(26.1 \%)$ & $22(71 \%)$ & \\
\hline
\end{tabular}

HG, high grade; LG, low grade; SD, standard deviation; UC, urothelial carcinoma.

Table 2. Reliability of Diagnostic Ureteroscopy Parameters: Selective Cytology, Lesion Appearance, and Tumor Biopsy.

\begin{tabular}{|c|c|c|c|c|c|}
\hline $\begin{array}{c}\text { Parameter } \\
\text { (n) }\end{array}$ & $\begin{array}{c}\text { Sensitivity } \\
(95 \% \mathrm{CI})\end{array}$ & $\begin{array}{c}\text { Specificity } \\
(95 \% \mathrm{CI})\end{array}$ & $\begin{array}{c}\text { PPV } \\
(95 \% \mathrm{Cl})\end{array}$ & $\begin{array}{c}\text { NPV } \\
(95 \% \mathrm{Cl})\end{array}$ & $\begin{array}{c}\text { Test Accuracy } \\
\text { (\%) }\end{array}$ \\
\hline Urine cytology ( $n=33)$ & $\begin{array}{c}0.6 \\
(0.38-0.81)\end{array}$ & $\begin{array}{c}0.84 \\
(0.65-1.04)\end{array}$ & $\begin{array}{c}0.86 \\
(0.67-1.04)\end{array}$ & $\begin{array}{c}0.58 \\
(0.35-0.80)\end{array}$ & 69.7 \\
\hline Lesion appearance $(n=37)$ & $\begin{array}{c}0.7 \\
(0.5-0.9)\end{array}$ & $\begin{array}{c}0.23 \\
(0.03-0.44)\end{array}$ & $\begin{array}{c}0.4 \\
(0.01-0.7)\end{array}$ & $\begin{array}{c}0.52 \\
(0.33-0.7)\end{array}$ & 54 \\
\hline Tumor biopsy ( $n=32)$ & $\begin{array}{c}0.53 \\
(0.29-0.76)\end{array}$ & $\begin{array}{c}0.8 \\
(0.6-1)\end{array}$ & $\begin{array}{c}0.75 \\
(0.51-0.99)\end{array}$ & $\begin{array}{c}0.6 \\
(0.35-0.81)\end{array}$ & 65 \\
\hline
\end{tabular}

$\mathrm{Cl}$, confidence interval; NPV, negative predictive value; PPV, positive predictive value.

decision of increasing importance. Several retrospective studies evaluated the role of platin-based $\mathrm{NAC}$, and promising pathological downstaging, complete response rates, and mortality reduction have been shown. ${ }^{6,8-12}$ However, the accuracy of ureteroscopic biopsy and its ability to provide reliable prognostic information is crucial for guiding UTUC treatment. ${ }^{13}$

\section{Selective Urine Cytology}

Since spontaneous bladder cytology has low sensitivity ${ }^{14}$ and high false positive, ${ }^{15}$ selective urine cytol- 
ogy is a common practice in the UTUC diagnostic process. Blute et al. ${ }^{16}$ and Streem et al. ${ }^{17}$ showed a positive brush urine cytology sensitivity of $90 \%$ (not determining grade) for the presence of UTUC. Regarding tumor grade, Skolarikos et al. found that positive urine cytology predicts HG in $67 \%$ of cases. ${ }^{18}$ Furthermore, in grade 2 (i.e. intermediate) biopsies, the combination of cytology with lesion biopsy improved the sensitivity and specificity of HG tumor detection from $43 \%$ to $55 \%$ and $23 \%$ to $85 \%$, respectively. ${ }^{18}$

We found that positive urine cytology is highly specific in predicting HG tumors $(84.6 \%)$ but has relatively low sensitivity (60\%) in ruling out $\mathrm{HG}$, with a practical accuracy of $69.7 \%$. It is worth noting that our center seeks to avoid achieving endoscopic brush cytology in favor of better visualization later on.

\section{Lesion Endoscopic Appearance}

Papillary endoscopic appearance is estimated to be $85 \%$, while the rest of the lesions are defined as "sessile/solid."19 In our cohort, surgeons described tumor lesions as "papillary" in $73 \%$ of the cases. However, only $52 \%$ were actually LG. On the other hand, our study provided a slightly better "solid" prediction value, namely $60 \%$. These results amount to a disappointingly low level of accuracy of $54 \%$. ElHakim et al. revised the urologist impressions of the lesion to predict tumor grade and found a slightly higher accuracy of 70\%.5 We agree with El-Hakim et al. 5 that therapeutic decisions should not be based only on tumor appearance, and that a biopsy must be explicitly taken when a solitary lesion is endoscopically treated or NAC is contemplated.

\section{Tissue Biopsy}

Histologic samples obtained by URS provide the best potential for predicting the final pathologic results, with a correlation of $78 \%-92 \% .{ }^{13,20,21}$ Our study had 20 cases with LG biopsies and 12 HG biopsies (including 3 carcinoma in situ [CIS] cases). However, in the final analysis, upgrading and downgrading occurred in $40 \%$ and $25 \%$ of the $\mathrm{LG}$ and $\mathrm{HG}$ cases, respectively, providing a relatively lower than expected $65 \%$ accuracy. This could be due to several possible reasons. First, upgrading might have occurred in cases where tissue biopsy sampled an LG area in a heterogeneous tumor hiding HG biology. Second, there might have been a non-uniform use of the lesion biopsy device on the part of the user. Lastly, grade diagnosis for biopsy and the final tumor pathology were determined by a different patholo- gist; UC grade interobserver reproducibility was previously documented as $70 \% .{ }^{22}$

With respect to biopsy devices, Lama et al. compared the performance of three contemporary ureteroscopic biopsy devices. His group found that even though a backloaded cup forceps and nitinol basket obtained a higher-quality specimen than standard cup forceps, this did not significantly impact diagnostic accuracy. ${ }^{23}$

\section{Final Pathological Stage}

Previous studies have demonstrated a correlation between UTUC grade and tumor stage. About $68 \%-$ $100 \%$ of UTUC patients with G1 tumors have a tumor stage of $\leq \mathrm{pT} 1$, while $62 \%-100 \%$ of patients with G3 tumors have stage $\geq \mathrm{pT}_{2}$. $^{24}$ In our cohort, $74 \%$ of LG UC patients had LG tumors in the final pathology, defined as $\leq \mathrm{T} 1$, while $\sim 72 \%$ of the HG UTUC patients had invasive disease $(\geq \mathrm{T} 2)$. When obtained using a standard endoscopic instrument, URS biopsies rarely contain muscle, which limits stage evaluation accuracy. ${ }^{7}$ As a result, defining the tumor grade provides more relevant pathological information that can aid in predicting tumor stage and can more accurately predict long-term survival at initial biopsy.

There is no doubt regarding the importance of distinguishing between high-risk and low-risk UTUC before the definitive treatment, particularly when considering RNU or NAC. A score combining the different preoperative factors (endoscopic appearance, cytology, biopsy, tumor size, and bladder grade status) can increase prediction accuracy in differentiating high versus low risk (grade and stage) in the final pathology. Due to rarity of UTUC, a multicenter trial is needed.

\section{LIMITATIONS}

Our study had several limitations. First, it was a single-center retrospective cohort study. Second, cytology, endoscopic appearance report, and tissue pathology were not available in all 54 patients, thereby preventing construction of a predictive model using these combined parameters. Third, our results do not include CT urography tumor dimensions, which could have given an additive predictive value for the final pathology. This last-mentioned measurement could not be uniformly defined for several reasons (multifocality, obstructed ureter and lack of secretion phase, the discrepancy between CT findings, and endoscopic description). Fourth, due 
to the lack of reporting, biopsy instruments could not be included in our data, a known factor in biopsy quality. It is essential to note that upper-tract tissues are routinely re-checked, and when indicated a second biopsy should be obtained. Lastly, patients who had received NAC were excluded from the study due to expected tumor biology changes that might have confounded our results. This could present a challenging problem since NAC is becoming common practice.

\section{CONCLUSIONS}

Direct observation demonstrating papillary lesions, negative cytology, and biopsy with LG findings are of low predictive value for classifying the final pathology UTUC grade and stage. Bladder UC grade, HG biopsy, and positive cytology were found to be better predictors of tumor grade. In light of the rising use of renal sparing surgery for low-risk UTUC and highrisk NAC, a reliable predictive model should be developed that accurately discriminates between high- and low-grade disease.

\section{REFERENCES}

1. Siegel RL, Miller KD, Jemal A. Cancer statistics, 2019. CA Cancer J Clin 2019;69:7-34. CrossRef

2. Rouprêt M, Babjuk M, Compérat E, et al. European Association of Urology guidelines on upper urinary tract urothelial carcinoma: 2017 update. Eur Urol 2018;73:111-22. $\underline{\text { CrossRef }}$

3. Huang C-C, Su Y-L, Luo H-L, et al. Gender is a significant prognostic factor for upper tract urothelial carcinoma: a large hospital-based cancer registry study in an endemic area. Front Oncol 2019;9:157. CrossRef

4. Szarvas T, Módos O, Horváth A, Nyirády P. Why are upper tract urothelial carcinoma two different diseases? Trans Androl Urol 2016;5:636-47. CrossRef

5. El-Hakim A, Weiss GH, Lee BR, Smith AD. Correlation of ureteroscopic appearance with histologic grade of upper tract transitional cell carcinoma. Urology 2004;63:647-50. $\underline{\text { CrossRef }}$

6. Liao RS, Gupta M, Schwen ZR, et al. Comparison of pathological stage in patients treated with and without neoadjuvant chemotherapy for high risk upper tract urothelial carcinoma. J Urol 2018;200:68-73. CrossRef

7. Margolin EJ, Matulay JT, Li G, et al. Discordance between ureteroscopic biopsy and final pathology for upper tract urothelial carcinoma. J Urol 2018;199: 1440-5. CrossRef
8. Martini A, Daza J, Poltiyelova E, et al. Pathological downstaging as a novel endpoint for the development of neoadjuvant chemotherapy for upper tract urothelial carcinoma. BJU Int 2019:124:665-71. CrossRef

9. Meng X, Chao B, Vijay V, et al. High response rates to neoadjuvant chemotherapy in high-grade upper tract urothelial carcinoma. Urology 2019;129:146-52. CrossRef

10. Almassi N, Gao T, Lee B, et al. Impact of neoadjuvant chemotherapy on pathologic response in patients with upper tract urothelial carcinoma undergoing extirpative surgery. Clin Genitourin Cancer 2018:16: e1237-42. $\underline{\text { CrossRef }}$

11. Matin SF, Margulis V, Kamat A, Wood CG. Incidence of downstaging and complete remission after neoadjuvant chemotherapy for high-risk upper tract transitional cell carcinoma. Cancer 2010;116:312734. CrossRef

12. Hosogoe S, Hatakeyama S, Kusaka A, et al. Platinumbased neoadjuvant chemotherapy improves oncological outcomes in patients with locally advanced upper tract urothelial carcinoma. Eur Urol Focus 2018;4:946-53. $\underline{\text { CrossRef }}$

13. Keeley FX, Kulp DA, Bibbo M, McCue PA, Bagley DH. Diagnostic accuracy of ureteroscopic biopsy in upper tract transitional cell carcinoma. J Urol 1997;157:337. PMID: 8976209

14. Konety BR, Getzenberg RH. Urine based markers of urological malignancy. J Urol 2001;165:600-11. CrossRef

15. Zincke H, Aguilo JJ, Farrow GM, Utz DC, Khan AU. Significance of urinary cytology in the early detection of transitional cell cancer of the upper urinary tract. $J$ Urol 1976;116:781-3. CrossRef

16. Blute ML, Segura JW, Patterson DE, Benson RC, Zincke H. Impact of endourology on diagnosis and management of upper urinary tract urothelial cancer. J Urol 1989;141:1298-301. CrossRef

17. Streem SB, Pontes JE, Novick AC, Montie JE. Ureteropyeloscopy in the evaluation of upper tract filling defects. J Urol 1985;136:353-5. CrossRef

18. Skolarikos A, Griffiths TRL, Powell PH, Thomas DJ, Neal DE, Kelly JD. Cytologic analysis of ureteral washings is informative in patients with grade 2 upper tract TCC considering endoscopic treatment. Urology 2003;61:1146-50. $\underline{\text { CrossRef }}$

19. Bagley DH, Rivas D. Upper urinary tract filling defects: flexible ureteroscopic diagnosis. J Urol 1990; 143:1196-200. CrossRef

20. Brown GA, Matin SF, Busby JE, et al. Ability of clinical grade to predict final pathologic stage in up- 
per urinary tract transitional cell carcinoma: implications for therapy. Urology 2007;70:252-6. CrossRef

21. Guarnizo E, Pavlovich CP, Seiba M, Carlson DL, Vaughan ED, Sosa RE. Ureteroscopic biopsy of upper tract urothelial carcinoma: improved diagnostic accuracy and histopathological considerations using a multi-biopsy approach. J Urol 2000;163:52-5. CrossRef

22. Nabebina TI, Rolevich AI, Dubrovsky AC, Krasny SA. Interobserver reproducibility in defining morphological parameters of patients with non-muscle-invasive bladder cancer with poor prognosis. Cancer Urology 2016;12:21-7. CrossRef

23. Lama ADJ, Safiullah S, Patel RM, et al. Multiinstitutional evaluation of upper urinary tract biopsy using backloaded cup biopsy forceps, a nitinol basket, and standard cup biopsy forceps. Urology 2018;117: 89-94. CrossRef

24. Cutress ML, Stewart GD, Wells-Cole S, Phipps S, Thomas BG, Tolley DA. single-center experience. BJU Int 2012;110:1608-17. CrossRef 